\title{
Welcome to Global Implementation Research and Applications
}

\author{
Rosalyn Bertram ${ }^{1} \cdot$ Dan Edwards ${ }^{2} \cdot$ Thomas Engell $^{3,4} \cdot$ Suzanne E. U. Kerns ${ }^{5} \cdot$ John $_{\text {Vvretveit }}{ }^{6}$. \\ Rodrigo Rojas-Andrade ${ }^{7}$. Mitchell Sarkies ${ }^{8}$. Caitlin R. Williams ${ }^{9}$
}

Received: 4 December 2020 / Accepted: 18 January 2021 / Published online: 30 January 2021

(c) The Author(s), under exclusive licence to Springer Nature Switzerland AG part of Springer Nature 2021

\section{Introduction}

Welcome to Global Implementation Research and Applications (GIRA), the journal of the Global Implementation Society (GIS). To improve outcomes across sectors and settings, GIS promotes global development and integration of effective implementation, improvement, and scaling practices. This journal serves as a global forum to share and learn from these efforts across disciplines, sectors, and settings. We seek manuscripts, as well as proposals for special issues, that address practical applications of implementation science and research, including but not limited to implementation challenges, perspectives, strategies, and outcomes.

Our diverse editorial board, some of whom contributed to this introduction, includes global representatives from behavioral health, child welfare, education, juvenile justice, public policy, and world health sectors, as well as purveyors

Rosalyn Bertram

bertramr@umkc.edu; bertramr@umsystem.edu

1 School of Social Work, University of Missouri-Kansas City, Kansas City, USA

2 Evidence Based Associates, Alexandria, USA

3 Regional Centre for Child and Adolescent Mental Health, Oslo, Norway

4 Department of Psychology, University of Oslo, Oslo, Norway

5 Graduate School of Social Work, University of Denver, Denver, USA

6 Improvement Implementation and Evaluation, LIME/MMC, Karolinska Institutet Medical University, Stockholm, Sweden

7 School of Psychology, Universidad Academia de Humanismo Cristiano, Santiago, Chile

8 Centre for Healthcare Resilience and Implementation Science, Australian Institute of Health Innovation, Faculty of Medicine, Health and Human Sciences, Macquarie University, Sydney, Australia

9 Department of Maternal and Child Health Gillings, School of Global Public Health, University of North Carolina, Chapel Hill, USA and researchers who shaped the emergence of implementation science. Journal contributors and readers include administrators, educators, practitioners, purveyors, researchers, and stakeholders, as well as those who shape policy and social initiatives. Because a global audience from diverse disciplines, sectors, and settings may not yet share a common understanding of implementation, we begin with a brief history of implementation as context for presenting the aims and scope of this unique journal.

\section{Origins of Implementation Research and Applications}

Increasingly a focus in the twenty-first century, the roots of implementation science can be traced to discussions of social process and the effectiveness of innovations in United States (US) and European agriculture, industry and health sectors (Rogers 1962). Following a decade of US social initiatives, the 1970s brought a flurry of studies that examined public policy implementation and identified multiple factors contributing to limited goal achievement (O'Toole 2000; Barrett 2004).

Identification of factors that influence adoption of policy innovations formed a foundation for knowledge translation, utilization, and technology transfer (Dearing and Kee 2012). Conducted in high-income countries (CDC 1999; Nilsen et al. 2013), policy implementation research focused across a broad range of sectors and issues, including public health (Sheikh et al. 2011) and social policy (Pressman and Wildavsky 1973; Winter 2006). These early explorations in implementation research and applications provided fertile ground for implementation science to emerge as a crossdisciplinary field of study.

Beginning in the 1980s and continuing through the 1990s, behavioral health, education, public health, and other social service programs began to focus upon interrelationships between outcomes for a population of concern, practice fidelity, and changes in organization and community 
supports. With perhaps the exception of the systems of care discourse in the United States (Stroul and Friedman 1986, 1994), these ideas tended to emerge within each sector or discipline.

\section{Impact of Evidence-Based Practice}

In the mid-to-late 1990s, an emphasis on evidence-based healthcare set the stage for an expansion of implementation research. Described as the conscientious, explicit, and judicious use of current best evidence in making decisions about the care of individual patients (Sackett et al. 1996), it spurred efforts to implement evidence in medical settings and ignited related discussions across sectors and disciplines (Bertram and Kerns 2019). Constructs of evidence-based treatments and enabling implementation practices soon emerged for psychosocial and behavioral health interventions.

To promote effective practice and enhance public health, the American Psychological Association (2006) defined evidence-based practice as the integration of the best available research with clinical expertise that considers patient characteristics, culture, and preference. Definitions of evidencebased practice as a process in medical settings (Sackett et al. 1996; Institute of Medicine 2001) influenced development of a similar definition in social work (Gibbs and Gambrill 2002), while in behavioral healthcare, Chambless and Ollendick (2001) asserted criteria for determining that a specific treatment model has an evidence-base.

Though useful in establishing a scientific foundation for practice innovations, these definitions did not systematically address the context necessary to support their effective delivery outside of tightly controlled research settings. Many noted a gap between evidence-based interventions and their implementation (Association of American Medical Colleges 1999). Impetus for closing that gap in healthcare came from a key US publication, Crossing the Quality Chasm (Institute of Medicine 2001), and in the United Kingdom from the Cooksey Redurlakport (2006).

In this context, the National Implementation Research Network released its seminal study of over 800 publications from three decades of empirical literature across disciplines, sectors, and settings (Fixsen et al. 2005). That study synthesized lessons from diverse efforts to disseminate and imbed effective practices, programs, and policies into frameworks that identified intervention components, implementation drivers, and stages of implementation. Concurrently, Implementation Science emerged as the first journal to focus on bridging that gap between research evidence and its adoption into practice. It defined its scope as the study of methods that promote systematic uptake of research findings and evidence-based practices to improve the quality and effectiveness of health services and care (Eccles and Mittman 2006). Soon thereafter, a consolidated framework to foster implementation of health services research findings into practice emerged (Damschroder et al. 2009) and Proctor and colleagues published a seminal paper on implementation outcomes research (Proctor et al. 2011).

\section{Impact in Global Health and Public Policy}

Implementation frameworks and science support efforts to address complex social challenges in different global settings and sectors. To achieve sustainable outcomes, implementation of initiatives, policies, and programs requires attention to evidence of both quality and replicability. Many note the importance of implementation science in global health (Sanders and Haines 2006; Theobald et al. 2018; Alonge et al. 2019). Further, resource challenges and demand for effective scale by stakeholders in low- and middle-income countries require distinct attention to implementation while possibly necessitating different kinds of implementation solutions (Rojas-Andrade et al. 2017; Yapa and Bärnighausen 2018).

A growing body of implementation research applies participatory approaches to support empowering communities for governance, policy design, and program management (Theobald et al. 2018). For example, co-creation, co-learning, and co-production of solutions, led by implementation practitioners, are strengthening health systems in South Africa, Tanzania, Ghana, Uganda, and Nepal (Gilson et al. 2014; Martineau et al. 2018). Some propose that sound implementation of effective policies, practices, and programs produces greater impact in low- or middle-income countries (Nolte and McKee 2004; Westgard and Fleming 2020). We believe implementation lessons from these settings may also prove informative to sectors in high-income nations.

\section{GIRA Aims and Scope}

Although opportunities to learn from implementation efforts emerge across settings, the few journals dedicated to implementation science have historically focused on specific sectors and disciplines. GIRA highlights and disseminates implementation research and applications from diverse sectors, global regions, and disciplines. We intentionally chart a broad path as a peer-reviewed global forum for the development, integration, and exchange of implementation knowledge and experience. We welcome manuscripts and proposals for special issues from diverse global settings, sectors, and disciplines. This includes but is not limited to agriculture, behavioral health, banking and finance, child welfare, education, justice, public health, social policy, and community development. 
We broadly view implementation as the act of carrying an intention of change into effect (Peters et al. 2013), whether that change be intervention, policy, procedure, technology system, service or other innovation. In addition to rigorous empirical studies and systematic data-informed presentations of implementation applications, we seek commentaries, perspectives, and other types of submissions from researchers, practitioners, purveyors, policymakers, administrators, and stakeholders. Manuscripts may focus upon, but are not limited to:

- Context analysis, readiness, and capacity development

- Development, application, and testing of implementation measures, strategies, and tools

- Implementation challenges, processes, and strategies

- Implementation theory, frameworks, or models

- Implementation planning, design, and evaluation

- Innovation fidelity, adaptation, dissemination, replication, and sustainability

- Policy development and implementation, system intervention, scale-up, and sustainability

Manuscripts may also address contemporary issues such as the exploration of approaches that challenge systemic racism or the adaptation of previous implementation strategies to pandemic conditions or in conditions of social unrest. We believe these efforts can offer implementation lessons and that applications of implementation science can make these efforts more effective and sustainable.

We publish scholarly papers, brief reports, commentaries, protocols, and systematic scoping reviews. Manuscripts should present perspectives and information in a clear manner understandable for those less familiar with research or implementation and the terminology of different disciplines, sectors, or settings. To support authors new to manuscript development and submission and those for whom English is not a primary language, we will offer writing resources. For guidance, please visit: https://www.springer.com/journ al/43477. We welcome your submissions, recommendations for special issues, comments, and questions.

\section{References}

Alonge, O., Rodriguez, D. C., Brandes, N., Geng, E., Reveiz, L., \& Peters, D. H. (2019). How is implementation research applied to advance health in low-income and middle-income countries? BMJ Global Health, 4(2), e001257.

American Psychological Association Presidential Task Force on Evidence-Based Practice. (2006). Evidence-based practice in psychology. American Psychologist, 61(4), 271-285.

Association of American Medical Colleges. (1999). Clinical research: A national call to action. Washington, DC: AAMC.

Barrett, S. M. (2004). Implementation studies: Time for a revival? Personal reflections on 20 years of implementation studies.
Public Administration, 82(2), 249-262. https://doi.org/10.111 1/j.0033-3298.2004.00393.x.

Bertram, R., \& Kerns, S. (2019). Selecting and implementing evidence-based practice: A practical program guide. Springer. https://doi.org/10.1007/978-3-030-11325-4.

Centers for Disease Control and Prevention. (1999). Ten great public health achievements - United States, 1990-1999. MMWR Morbidity and Mortality Weekly Report, 48(12), 241-243.

Chambless, D. L., \& Ollendick, T. H. (2001). Empirically supported psychological interventions: Controversies and evidence. Annual Review of Psychology, 52(1), 685-716. https:// doi.org/10.1146/annurev.psych.52.1.685.

Cooksey, D. (2006). A review of UK health research funding. The Stationery Office. https://doi.org/10.1136/bmj.39059.44412 0.80 .

Damschroder, L. J., Aron, D. C., Keith, R. E., Kirsh, S. R., Alexander, J. A., \& Lowery, J. C. (2009). Fostering implementation of health services research findings into practice: A consolidated framework for advancing implementation science. Implementation Science, 4(1), 1-15. https://doi.org/10.1186/1748-5908-4-50.

Dearing, J. W., \& Kee, K. F. (2012). Historical roots of dissemination and implementation science. Dissemination and Implementation Research in Health: Translating Science to Practice, 55, 71. https ://doi.org/10.1093/oso/9780190683214.003.0003.

Eccles, M. P., \& Mittman, B. S. (2006). Welcome to Implementation Science. Implementation Science, 1, 1. https://doi. org/10.1186/1748-5908-1-1.

Fixsen, D. L., Naoom, S. F., Blase, K. A., Friedman, R. M., \& Wallace, F. (2005). Implementation research: A synthesis of the literature. Tampa, FL: University of South Florida, Louis de la Parte Florida Mental Health Institute, The National Implementation Research Network (FMHI Publication \#231).

Gibbs, L., \& Gambrill, E. (2002). Evidence-based practice: Counterarguments to objections. Research on Social Work Practice, 12(3), 452-476. https://doi.org/10.1177/1049731502012003007.

Gilson, L., Elloker, S., Olckers, P., \& Lehmann, U. (2014). Advancing the application of systems thinking in health: South African examples of a leadership of sensemaking for primary health care. Health Research Policy and Systems, 12(1), 30. https://doi. org/10.1186/1478-4505-12-30.

Institute of Medicine. (2001). Crossing the quality chasm: A new health system for the 21 st century. Washington, DC: National Academies Press. https://doi.org/10.17226/10027.

Martineau, T., Raven, J., Aikins, M., Alonso-Garbayo, A., Baine, S., Huss, R., ... Wyss, K. (2018). Strengthening health district management competencies in Ghana, Tanzania and Uganda: Lessons from using action research to improve health workforce performance. BMJ Global Health, 3(2), e000619. https://doi. org/10.1136/bmjgh-2017-000619

Nolte, E., \& McKee, M. (2004). Does health care save lives? Avoidable mortality revisited. London: The Nuffield Trust.

O'Toole, L. J., Jr. (2000). Research on policy implementation: Assessment and prospects. Journal of Public Administration Research and Theory, 10(2), 263-288. https://doi.org/10.1093/oxfordjour nals.jpart.a024270.

Peters, D. H., Adam, T., Alonge, O., Agyepong, I. A., \& Tran, N. (2013). Implementation research: What it is and how to do it. $B M J, 347$, f6753. https://doi.org/10.1136/bmj.f6753.

Pressman, J., \& Wildavsky, A. (1973). Implementation. Berkeley: University of California Press.

Proctor, E., Silmere, H., Raghavan, R., Hovmand, P., Aarons, G., Bunger, A., ... Hensley, M. (2011). Outcomes for implementation research: Conceptual distinctions, measurement challenges, and research agenda. Administration and Policy in Mental Health and Mental Health Services Research, 38(2), 65-76. https://doi. org/10.1007/s10488-010-0319-7. 
Rojas-Andrade, R., Leiva-Bahamondes, L., Vargas, A. M. B., \& Squicciarini-Navarro, A. M. (2017). Efectos de la fidelidad de la implementación sobre los resultados de una intervención preventiva en salud mental escolar: un análisis multinivel. Psychosocial Intervention, 26(3), 147-154.

Rogers, E. M. (1962). Diffusion of innovations (1st ed.). NYC: Free Press.

Sackett, D. L., Rosenberg, W. M., Gray, J. M., Haynes, R. B., \& Richardson, W. S. (1996). Evidence based medicine: What it is and what it isn't. $B M J, 312,71-72$.

Sanders, D., \& Haines, A. (2006). Implementation research is needed to achieve international health goals. PLoS Medicine, 3(6), e186. https://doi.org/10.1371/journal.pmed.0030186.

Sheikh, K., Gilson, L., Agyepong, I. A., Hanson, K., Ssengooba, F., \& Bennett, S. (2011). Building the field of health policy and systems research: Framing the questions. PLoS Medicine, 8(8), e1001073. https://doi.org/10.1371/journal.pmed.1001073.

Stroul, B. A., \& Friedman, R. M. (1986). A system of care for severely emotionally disturbed children \& youth. Washington, DC: Georgetown University Child Development Center.
Stroul, B. A., \& Friedman, R. M. (1994). A system of care for children and youth with severe emotional disturbances. Washington, DC: CASSP Technical Assistance Center, Center for Child Health and Mental Health Policy, Georgetown University Child Development Center.

Theobald, S., Brandes, N., Gyapong, M., El-Saharty, S., Proctor, E., Diaz, T., ... Bharal, S. (2018). Implementation research: New imperatives and opportunities in global health. The Lancet, 392(10160), 2214-2228. https://doi.org/10.1016/S0140 $-6736(18) 32205-0$.

Westgard, C., \& Fleming, W. O. (2020). The use of implementation science tools to design, implement, and monitor a community-based mhealth intervention for child health in the amazon. Frontiers in Public Health, 8, 411.

Winter, S. C. (2006). Implementation. In B. G. Peters \& J. Pierre (Eds.), Handbook of public policy (pp. 151-166). Thousand Oaks, CA: Sage. https://doi.org/10.4135/9781848608054.n9.

Yapa, H. M., \& Bärnighausen, T. (2018). Implementation science in resource-poor countries and communities. Implementation Science, 13(1), 154. https://doi.org/10.1186/s13012-018-0847-1. 